\title{
The effect of selected music on blood pressure and pulse rate of first year college students in a suggestopaedic course
}

\section{Mervyn Garlick}

Music is an important component of suggestopaedic teaching. However, little research has been done into the kind of music which is most effective, particularly in terms of the physiological effect on students.

The writer describes an experiment in which the effect on blood pressure and pulse rate on a group of students caused by various kinds of music is measured. The results are analysed and suggestions for further research in this field are made.

Musiek vorm 'n belangrike komponent van suggestopediese onderrig. Daar is egter weinig navorsing gedoen om te bepaal watter soort musiek die effektiefste sal wees, veral ten opsigte van die fisiologiese uitwerking op studente.

Die skrywer beskryf 'n eksperiment waarin verskeie soorte musiek gebruik is om die uitwerking daarvan op die bloeddruk en polsslag van 'n groep studente vas te stel. Die resultate is ontleed en voorstelle vir verdere navorsing op dié gebied word gemaak.

\section{Introduction}

Traditional models of language acquisition recommend a gradual and gentle way of introducing students to a new language. The proponents of these models argue that, at the beginning of a course of instruction, only a few easy words should be introduced with some rules of syntax. They maintain that all or most of the material of each lesson must be mastered, tested and drilled and that close attention to details of spelling, pronunciation and word selection is essential. Their fear is that the learners may drown or their memory systems collapse from an overload of input. Karl Sandberg (in Blair 1982) argues that while it is wise to be concerned about overloading the learning system, it is not wise to leave out the ability of the mind to select from a rich environment that which it needs and is currently relevant to it. He suggested that this small quantity of input and gradual progression creates a deficient learning environment and provides little for the student to select from. He called this the "empty bin" approach and contrasted this with the "full bin" approach in which a great volume of material is introduced and the opportunity given to the learner to select from it that which he finds meaningful and useful.

The past few decades have shown great advances in the understanding of first and second language acquisition, of learning psychology and of language itself. The resultant school of thought sees the learner rather than the subject matter as central to the learning process, views the learner not as a disembodied brain, but as a whole person and sees ego-involvement as a primary force for or against 
learning, with the acquisition of skill or knowledge resulting not simply from the injection of subject matter reinforced by drill, but requiring a readiness (from the learner) before it can be assimilated and become functional. In effect, this school rejects both the behavioural and cognitive models of learning which focus more on the brain than on the whole person in a dynamic social matrix. This approach introduces and stresses the dimension that takes into account, and deals with, the intrapersonal and interpersonal aspects of the learning process.

Georgi Lozanov, a Bulgarian psychiatrist who can be seen as a member of this resultant school of thought, has developed an accelerative learning and teaching system known as Suggestopaedia, a holistic teaching system based on Suggestology, the science of suggestion. Lozanov himself described Suggestopaedia as:

The global approach to personality, the "volumely" (not linearly) organized instruction, the simultaneous participation of man's mental and emotional sides, the simultaneous participation of the left and right hemispheres of the brain, as well as that of the cortex and subcortex - all these are of great importance for the global and many-sided influence of suggestopedy over the personality (Lozanov 1978:225).

\section{The role of music in Suggestopaedia}

The selected use of music is acknowledged as an essential part of suggestopaedic learning and teaching (Brislan 1985:25) and, satisfying emotional and aesthetic needs, it reinforces the ritualistic effect of the class, particularly the concert sessions, secures the authority principie and involves the whole brain. It also enhances the general suggestive atmosphere and thus leads to positive expectations on the part of the students. It also assists with relaxation which Lozanov maintains is the crux of the matter as it facilitates the by-passing of the anti-suggestive barriers, enhances retention and by extension, optimizes learning and retention. Music acts in harmony with other suggestive factors and supports the learning process by acting as a medium (carrier) to activate the reserve capacities of the mind.

As a part of the total conscious-unconscious duality of the learning setting, it contributes to the non-specific mental reactivity which activates the reserves of the mind (Caskey in Botha 1986:147).

Apart from helping to create superior cerebral activity "by assisting with lateralization of the content in the left hemisphere and the encoding of it in the right hemisphere" (Dhority 1984:9-4) music is used to enhance the creation of the second plane of the suggestive atmosphere and to defocus the memorization process. It also assists in the flow and presentation of the dialogue (content) as well as creating a non-threatening environment wherein the student can gather impressions of a non-specific variety.

\section{The concert session}

This comprises the first and second concerts during which large amounts of the same material are presented; each concert, however, uses different music and a different communication style. The facilitator treats these concerts with a certain amount of ritual while the students are behaviourally passive and make no conscious effort to memorize or understand the programme being presented. The students are given a text which they follow during the first concert.

As in Ancient Greece, two forms of music were used - one appealing more to the emotions, one appealing more to the intellect . . . also bears considerable resemblance to the sessions of modern music therapy in which musical selections are chosen to provoke first arousal, then security (Bancroft 1985:15).

Thus the first concert uses music and a style of speech which are both more "emotional" in nature while the second concert uses music and speech patterns regarded (in the suggestopaedic context) as "mathematical" or "philosophical" (Bancroft 1978:153). 


\section{The first concert}

Music from the classical or romantic periods is used during this concert and while the selected music is played, the facilitator reads the text aloud following a certain rhythmic pattern almost as if he were paying no attention to the meaning of the words. His style of delivery is dictated by the rhythm, tempo, dynamics and phrasing of the music and he integrates his voice with it (the music) as though it were another musical instrument. When concerted music is used, the facilitator intones with the solo instrument and is silent during the tutti sections. (The "tutti" sections are those sections in a musical composition where the orchestra plays but not the solo instrument.) The students follow the text during the reading; during the pauses (in the reading) they are able to glance at the translation or explanation on the right hand side of the text. They are also encouraged to repeat words and phrases softly to themselves and to visualize the scenes as vividly as possible.

Graphically, the first concert presentation may be represented as follows
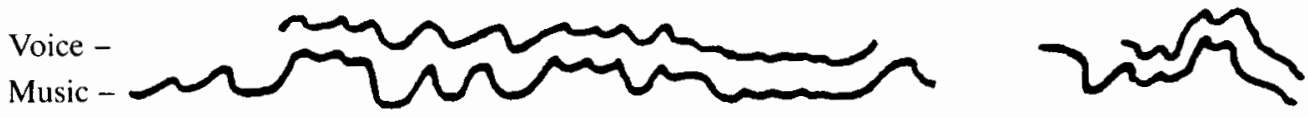

(Dhority 1984:9-5)

\section{The second concert}

During this concert, the material to be read remains the same as in the first concert but the music now selected is from the baroque period. The facilitator reads the material in a natural tone of voice guided by its meaning and not by the music's tempo, dynamics, rhythm or phrasing. The students are invited to put their texts aside, to relax in a comfortable position with their eyes closed and, while listening to the music, to allow their minds to wander freely.

Graphically, the second concert presentation may be represented as follows
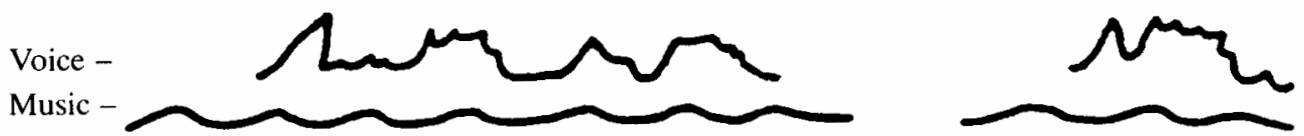

(Dhority 1984:9-5)

\section{On the choice of music for suggestopaedic sessions - some considerations}

Some kinds of music appear to be more suited for use in a suggestopaedic session than other kinds and a brief overview of some of the criteria for choice are therefore noted below.

Music is a holistic system and because its elements cannot exist one without the other, it is problematic to attempt to say which element is more important than another. As a general guide, the music chosen for mental relaxation must have "relaxation" qualities. First Concert music should be classical or romantic in period and generally concerted, while music for the Second Concert is baroque music. The musical element of rhythm is able to cause physical responses which can lead to stimulating or depressing effects on the rhythmic systems of the body and the most steadying pulse appears to be quadruple pulse. Other pulses such as triple, quintuple and sextuple seem to lead to a feeling of restlessness. Normal human heartbeat in all cultures appears to be between 70 and 80 beats per minute (Bancroft 1985:9) and using music with an approximate pulse of 60 beats per minute for relaxation leads to a feeling of calm and tranquillity. It has been noted (Bancroft 1985:9) that the subtle rhythms of classical Indian music played on the sitar appeal to the intellect and that, in Indian philosophy, a beat of 60 to the minute is considered ideal for meditation. Bancroft notes that it is possibly the $1: 4$ ratio of heart rate to breathing that makes quadruple time (at 60 beats per minute) 
the most useful for a steadying effect. In addition, she also notes that, apart from a slow regular rhythm, relaxation music should have even dynamics and no dissonance. Dissonant harmonies and abrupt dynamic changes appear to increase physical activity and decrease mental activity and, within the Western system of musical scales, the common chords (chords I, IV and V in the major mode) have a soothing effect while the minor chords are used, in some instances, to indicate distress. Consonance, as represented by the common chords (major chords), is said to represent order and serenity while dissonant chords cause stress. Major modes appear to create feelings of happiness and lightness while minor modes are thought to provoke sadness and darkness. The harmonic language of the baroque and classical periods is described as consonant while those of the romantic period are regarded as "complex and/or engulfing" (Bancroft 1985:10). One should be aware, however, that within these periods, the classical period, as represented by Haydn and Mozart, was a reaction to the highly dissonant writing of the late baroque period as characterized by the writings of JS Bach, that the baroque period was a period which started as a reaction to modal writing and that the baroque period can itself be divided into early, middle and late baroque. Further, although Beethoven is regarded as a "classical" composer, his writing can also be thought of as bridging the period between the classical period and the romantic period and the subsequent increase of dissonance which, in itself, is related to the development of the pianoforte.

\section{Literature review}

As has been indicated above, music plays an important role in Suggestopaedia. The following review of the relevant literature indicates that many experiments involving one or other aspect of music in a suggestopaedic setting have been conducted.

Bordon and Schuster (1976) investigated the effects of a suggestive learning climate, synchronized breathing and music on the learning and retention of Spanish words.

Schuster and Pansegrau (1977) studied the effect of background music relative to speaking volume.

Schuster and Mouzon (1982) evaluated the effect of three different types of music on vocabulary learning.

Gamble et al (1982) attempted to determine the effects of relaxation training and music on creativity.

Stein et al (1982) investigated the effect on retention of vocabulary when music and imagery were used to accelerate learning.

Render et al (1984) studied the effects of guided relaxation and baroque music on college students' test performance.

Schuster (1985) experimented with the effect of background music on learning words.

It appears that Lozanov and his colleagues had researched the physiological effects of music in a suggestopaedic setting:

... specially selected music . . . adapted to the requirements of suggestopaedic teaching and learning are used.

. . . the musical programme for each session is chosen by our fellow-researcher E Gateva. Its effect is experimentally checked both in the electro-physiological laboratory and in the foreign language courses.

As a result of this research, Lozanov (1978) presented a list of music "included in our programmes".

Under "Pulse and blood pressure", sub-heading under "Suggestopedy and Students' Health", Lozanov noted:

When the data obtained from all the investigations is analysed, a tendency can be observed toward a delay of an average five beats per minute in the pulse, and an average drop of four divisions of the mercury column in the blood pressure. 
He wrote that these readings were measured before and after lessons but there is no mention of the kind of music used during the measurement. Ostrander and Schroeder (1979) have noted that during a concert session of slow baroque music (60 beats per minute), during intense mental activity (learning 100 foreign words), the pulse slowed down by 5 beats per minute and that the blood pressure dropped by 4 divisions of the mercury column on average. They quote their source as "Suggestology" by G Lozanov, yet there does not appear to be any verification in Lozanov's book "Suggestology and Outlines of Suggestopedy" that the drop in blood pressure and pulse rate was measured during the playing of slow baroque music. This book is, however, a revised and updated translation of "Suggestology" published in Sofia, Bulgaria (1971) and it is possible that during the revision of the book, that particular detail was omitted.

This is the only physiological research with particular reference to blood pressure, pulse rate and music in a suggestopaedic setting. There is, however, a non-suggestopaedic study (Blanchard 1979) quoted in some articles in the Journal of the Society for Accelerative Learning and Teaching, core journal for Suggestopaedia. Blanchard experimented with the effect of music on blood pressure, heart rate and final exam scores of university students and reported that classical music and rock ' $n$ ' roll music significantly enhanced final exam scores compared with the control group who had no music during the exam. It is perhaps useful to present the comparative analysis and to note that:

\section{the control group's -}

- mean score was the lowest

- pulse increased (before to after) by $11.3 \mathrm{bpm}$ (mean)

- systolic pressure increased (before to after) by 29 (mean)

- diastolic pressure increased (before to after) by 50 (mean)

\section{the rock 'n' roll group's -}

- mean score was significantly higher than the control group's mean exam score

- pulse increased by .3 bpm (mean) (before to after)

- systolic pressure stayed the same (before to after)

- diastolic pressure increased (before to after) by 3

\section{the classical music group's -}

- mean exam score was the highest and slightly higher than the rock 'n roll group

- pulse decreased by .4 bpm (mean) (before to after)

- systolic pressure stayed the same (before to after) (mean)

- diastolic pressure (before to after) increased by 1 (mean)

\section{Experimental design}

From the above overview it appears that

- the use of specially selected music induces relaxation in a suggestopaedic setting

- the relaxation thus induced can be measured by a decrease in both blood pressure and pulse rate

- Brislan (1984:43), Redmond (1984:152, 155), Schuster (1985:22) and Stein et al (1982:361) either state specifically, or intimate, that there is a need for further research concerning the effect of music in a suggestopaedic setting.

Therefore the following hypotheses were formulated:

1 Certain kinds of music will induce more relaxation as measured by Blood Pressure and Pulse Rate than other kinds.

2 The music inducing most relaxation as measured by Blood Pressure and Pulse Rate will have common characteristics. 


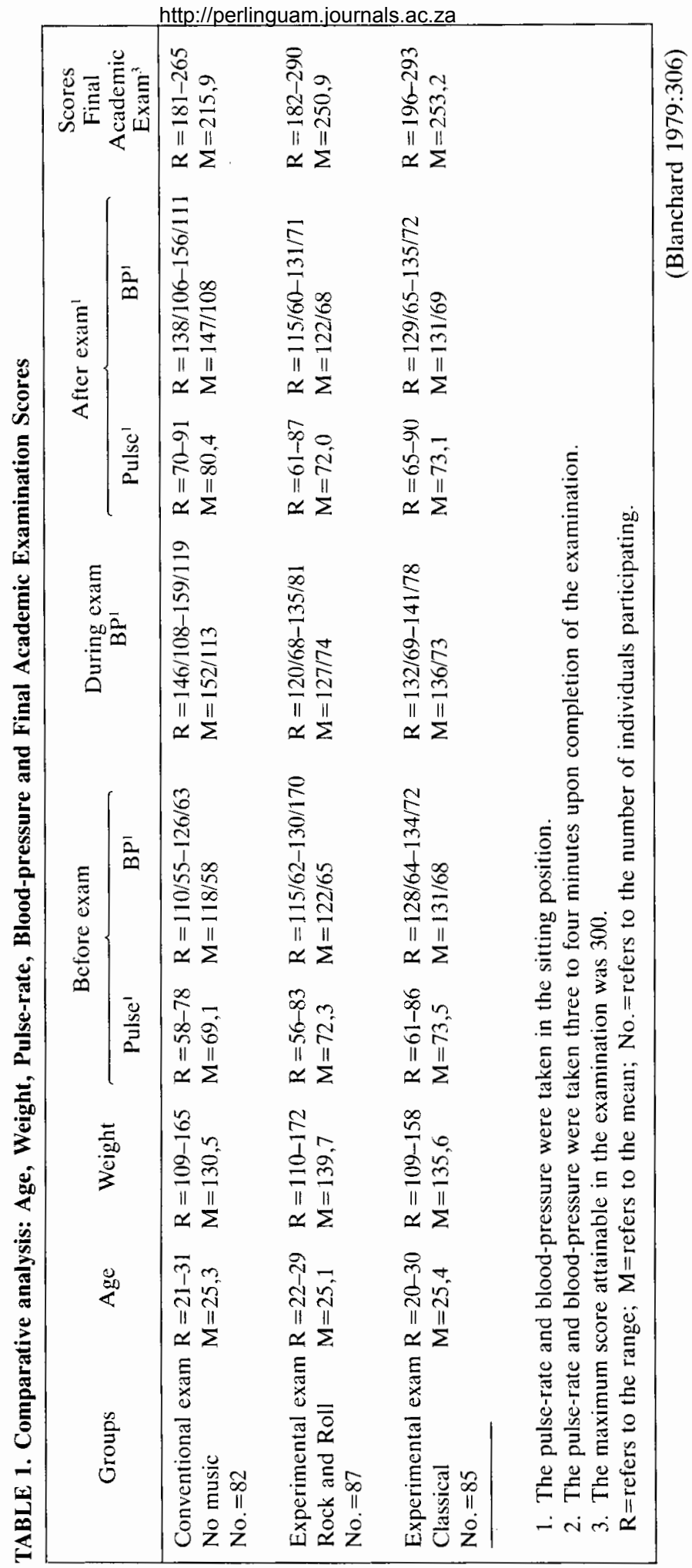




\section{Conduct of the experiment}

Of 32 students registered for the geography course at Cape Town Teachers' College, 14 were chosen at random for the suggestopaedic geography course. The 14 students consisted of 7 males and 7 females. One female student left the College in March 1987, so the number was therefore reduced to 13.

Number of students: $\quad 13$

Males: $\quad 7$

Females: $\quad 6$

Average age at commencement of course: 19 years 1 month

Average age at conclusion of course: 19 years 4 months

The course extended over three months.

Blood Pressure and Pulse Rates were measured by a team consisting of a medical doctor and two nurses at the first session of each of the 10 weeks of the course.

The choice of music

The music chosen for the first five lessons was repeated during the second five lessons:

\section{Weeks}

\begin{tabular}{|c|c|c|c|}
\hline $1 \& 6$ & $\begin{array}{l}\text { Mental Relaxation } \\
\text { First Concert } \\
\text { Second Concert }\end{array}$ & $\begin{array}{l}\text { Pachelbel } \\
\text { Tschaikovsky } \\
\text { Relaxing with the Classics }\end{array}$ & $\begin{array}{l}\text { - Canon in D } \\
\text { - Piano Concerto No } 1 \\
\text { - Mixed Collection of baroque largo } \\
\text { and adagio movements }\end{array}$ \\
\hline $2 \& 7$ & $\begin{array}{l}\text { Mental Relaxation } \\
\text { First Concert } \\
\text { Second Concert }\end{array}$ & $\begin{array}{l}\text { Halpern } \\
\text { Beethoven } \\
\text { Bach, JS }\end{array}$ & $\begin{array}{l}\text { - Spectrum Suite } \\
\text { - Violin Concerto Op } 61 \\
\text { - Orchestral Suite No } 1 \text { in C major }\end{array}$ \\
\hline $3 \& 8$ & $\begin{array}{l}\text { Mental Relaxation } \\
\text { First Concert } \\
\text { Second Concert }\end{array}$ & $\begin{array}{l}\text { Haydn } \\
\text { Vivaldi, A }\end{array}$ & $\begin{array}{l}\text { - Collection of baroque slow } \\
\text { movements } \\
\text { - Trumpet Concerto in E flat major } \\
\text { - The Four Seasons }\end{array}$ \\
\hline $4 \& 9$ & $\begin{array}{l}\text { Mental Relaxation } \\
\text { First Concert } \\
\text { Second Concert }\end{array}$ & $\begin{array}{l}\text { Kobialka, D } \\
\text { Mozart } \\
\text { Handel }\end{array}$ & $\begin{array}{l}\text { - Dream Passage } \\
\text { - Piano Concerto K488 } \\
\text { - Water Music }\end{array}$ \\
\hline $5 \& 10$ & $\begin{array}{l}\text { First Concert } \\
\text { Second Concert }\end{array}$ & $\begin{array}{l}\text { Mozart } \\
\text { Corelli }\end{array}$ & $\begin{array}{l}\text { - A composition using the alto } \\
\text { metallophone } \\
\text { - Clarinet Concerto K } 622 \\
\text { - Concerti Grossi Numbers } 1,11 \text { \& } \\
\quad 12\end{array}$ \\
\hline
\end{tabular}

\section{REASONS FOR CHOICE OF MUSIC}

\section{Mental Relaxation}

Pachelbel Canon in D This piece is traditionally regarded as relaxing-music and has been used in previous suggestopaedic classes as well as in Music Therapy. One of the reasons for its so-called relaxing properties is its use of a descending "groundbass" figure.

Spectrum Suite, Halpern This music is included in "Suggestopaedia for Second Language Acquisition" (Botha, 1986:377). Use is made of the electric piano's "suspended" soundeffect and the music is described on the cover of the tape-cassette as "An antifrantic alternative' Music for relaxation, self-healing and pure listening pleasure". 
Andante (Side A) This is a collection of baroque slow movements and its choice was based on the supposition in Suggestopaedia that baroque slow movements and adagio movements have a relaxing effect.

Dream Passage, Kobialka The music was composed to create a dreamlike quality in the listener. Use is made of instrumentation which has a quality of sound "suspension" and the rhythmic pulse is ill-defined.

Soh Me This was a "home-made" tape using the two pitches of $\mathrm{G}(\mathrm{Soh})$ and $\mathrm{E}(\mathrm{Me})$; the falling minor third. These pitches were played on an alto metallophone of which the sound quality is also one of "suspension". The rhythmic pulse is extremely ill-defined and the music moves very slowly.

\section{FIRST CONCERT MUSIC}

\section{Tschaikovsky Piano Concerto No 1, B flat minor, Opus 23}

This piece of music is listed in Lozanov's book (1978:270) and is a piece that is considered to fall in the Romantic period. The reason for its choice is purely personal; the writer, at the beginning of 1987, attended a suggestopaedic course and, when this music was played, was extremely disturbed by it as accompaniment to reading of content.

\section{Beethoven Violin Concerto, D major, Opus 61}

Bancroft (1985:11) cites research conducted by a Frenchman, Dr Alfred Tomatis, who claims that the violin is the most soothing of all instruments owing to its high frequencies. This piece of music is also suggested by Lozanov (1978:270) and falls in the classical period.

\section{Haydn Trumpet Concerto, E flat major}

This piece of music was chosen because it represents a member of the brass family of musical instruments. It also falls in the classical period.

\section{Mozart Piano Concerto, A major, K488}

This piece of music represented the classical Piano Concerto, as opposed to the romantic Piano Concerto represented by the Tschaikovsky Piano Concerto.

\section{Mozart Clarinet Concerto, A major, K622}

This piece of music was chosen because it represents a member of the woodwind family of musical instruments. It falls in the classical period.

\section{SECOND CONCERT MUSIC}

The only criterion in the choice of music was that, according to the principles for choice of music, it had to be of the baroque period.

Because of the practical problems involved in the students' pulse rate and blood pressure, one should be aware when interpreting the results, that these measurements were taken during the first two to three minutes of second concert music. Therefore the following "couplings" must be borne in mind.

Tschaikovsky Piano Concerto

Beethoven Violin Concerto

Haydn Trumpet Concerto

Mozart Piano Concerto K488

Mozart Clarinet Concerto K622
(Relaxing with the Classics)

(Bach, JS, Orchestral Suite No $1 \mathrm{C}$ major)

(Vivaldi, A, The Four Seasons)

(Handel, GF, Water Music)

(Corelli Concerti Grossi Nos 1, 11, 12)

\section{EXPECTATIONS}

It was expected that certain pieces of the selected music would affect the students more than other pieces of the selected music. 


\section{EVENT A}

\section{Mental Relaxation}

It was expected that the two baroque pieces would effect the greatest change, especially the Pachalbel, because this music is regarded, in Suggestopaedia, as being "ideal" relaxation music. It was hoped, not expected, that Soh-Me would indicate some change because, in terms of the infantilization principle, this interval, the falling minor third, is the first pitch difference which a very young child "sings".

\section{EVENT B}

\section{First Concert}

In view of the writer's personal reaction to the Tschaikovsky, it was expected that this piece would effect the least change. It was expected that the greatest change would be effected by the Beethoven Violin Concerto because the violin, as indicated above, is the most soothing of all instruments owing to its high frequencies.

TABLE 2 The Effect of Selected Music on Students' Pulse Rate, Blood Pressure (diastolic) and Blood Pressure (systolic)

\begin{tabular}{|c|c|c|c|c|c|c|c|c|c|c|}
\hline \multirow[b]{2}{*}{ EVENT A } & \multicolumn{3}{|c|}{ PULSE } & \multicolumn{3}{|c|}{$\begin{array}{c}\text { BLOOD PRESSURE } \\
\text { Systolic } \\
\end{array}$} & \multicolumn{3}{|c|}{$\begin{array}{c}\text { BLOOD PRESSURE } \\
\text { Diastolic }\end{array}$} & \multirow[b]{2}{*}{$\begin{array}{c}\text { TOTAL } \\
\text { NUMBER } \\
\text { OF } \\
\text { STUDENTS } \\
\end{array}$} \\
\hline & \begin{tabular}{|l|}
\multicolumn{1}{c|}{ No. } \\
Students \\
Affected \\
DOWN \\
\end{tabular} & SAME & $\begin{array}{c}\text { No. of } \\
\text { Students } \\
\text { Affected } \\
\text { UP }\end{array}$ & \begin{tabular}{l}
\multicolumn{1}{c}{ No. } \\
Students \\
Affected \\
DOWN \\
\end{tabular} & SAME & $\begin{array}{c}\text { No. of } \\
\text { Students } \\
\text { Affected } \\
\text { UP } \\
\end{array}$ & \begin{tabular}{|c|} 
No. \\
Students \\
Affected \\
DOWN \\
\end{tabular} & SAME & \begin{tabular}{|c|} 
No. of \\
Students \\
Affected \\
UP \\
\end{tabular} & \\
\hline PACHALBEL & 4 & 4 & 5 & 8 & 5 & 0 & 0 & 8 & 5 & 13 \\
\hline HALPERN & 8 & 2 & 2 & 8 & 4 & 0 & 4 & 7 & 1 & 12 \\
\hline ANDANTE & 6 & 5 & 1 & 6 & 5 & 1 & 3 & 6 & 3 & 12 \\
\hline KOBIALKE & 6 & 4 & 1 & 11 & 2 & 0 & 7 & 3 & 3 & 13 \\
\hline SOH ME & 10 & 3 & 0 & 4 & 8 & 1 & 3 & 5 & 5 & 13 \\
\hline $\begin{array}{l}\text { EVENT B } \\
\text { TSCHAIKOVSKY }\end{array}$ & 7 & 4 & 2 & 5 & 4 & 4 & 9 & 3 & 1 & 13 \\
\hline BEETHOVEN & 8 & 3 & 1 & 7 & 4 & 1 & 8 & 3 & 1 & 12 \\
\hline HAYDN & 7 & 4 & 2 & 4 & 5 & 4 & 3 & 8 & 2 & 13 \\
\hline MOZART K488 & 8 & 4 & 1 & 7 & 3 & 3 & 8 & 3 & 2 & 13 \\
\hline MOZART K622 & 8 & 5 & 0 & 6 & 5 & 2 & 9 & 4 & 0 & 13 \\
\hline
\end{tabular}

PULSE RATE: DOWN; any change greater than $4 \mathrm{bpm}$ UP; any change greater than $4 \mathrm{bpm}$

BLOOD PRESSURE, SYSTOLIC: DOWN; any change greater than $4 \mathrm{~mm}$ UP; any change greater than $4 \mathrm{~mm}$

BLOOD PRESSURE, DIASTOLIC: DOWN; any change greater than $3 \mathrm{~mm}$ UP; any change greater than $3 \mathrm{~mm}$

\section{Discussion of results}

The following should be noted when interpreting the results

\section{Blood Pressure:}

Systolic Pressure

- this measurement is regarded as being more sensitive to change in the short term

Diastolic Pressure

- this measurement is regarded as measuring change over a longer period and a change is regarded as more significant in medical terms

More Relaxation: this term is taken to mean "affecting the most number of students". 


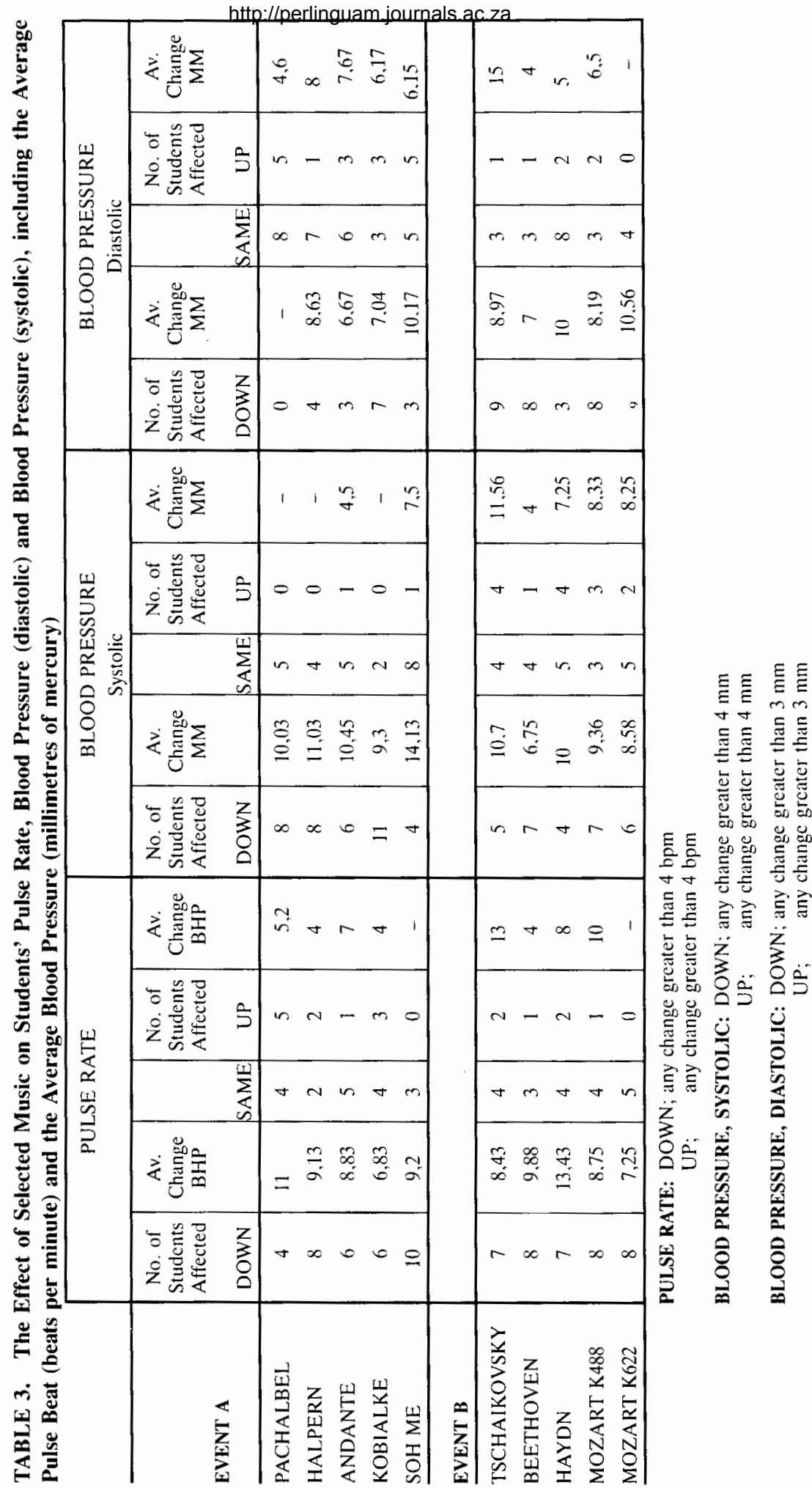


TABLE 4. The Effect of Selected Music on Students' Pulse Rate, Blood Pressure (diastolic and systolic), indicating the greatest number of students affected to least number of students affected (top to bottom) for Event $A$ and Event $B$.

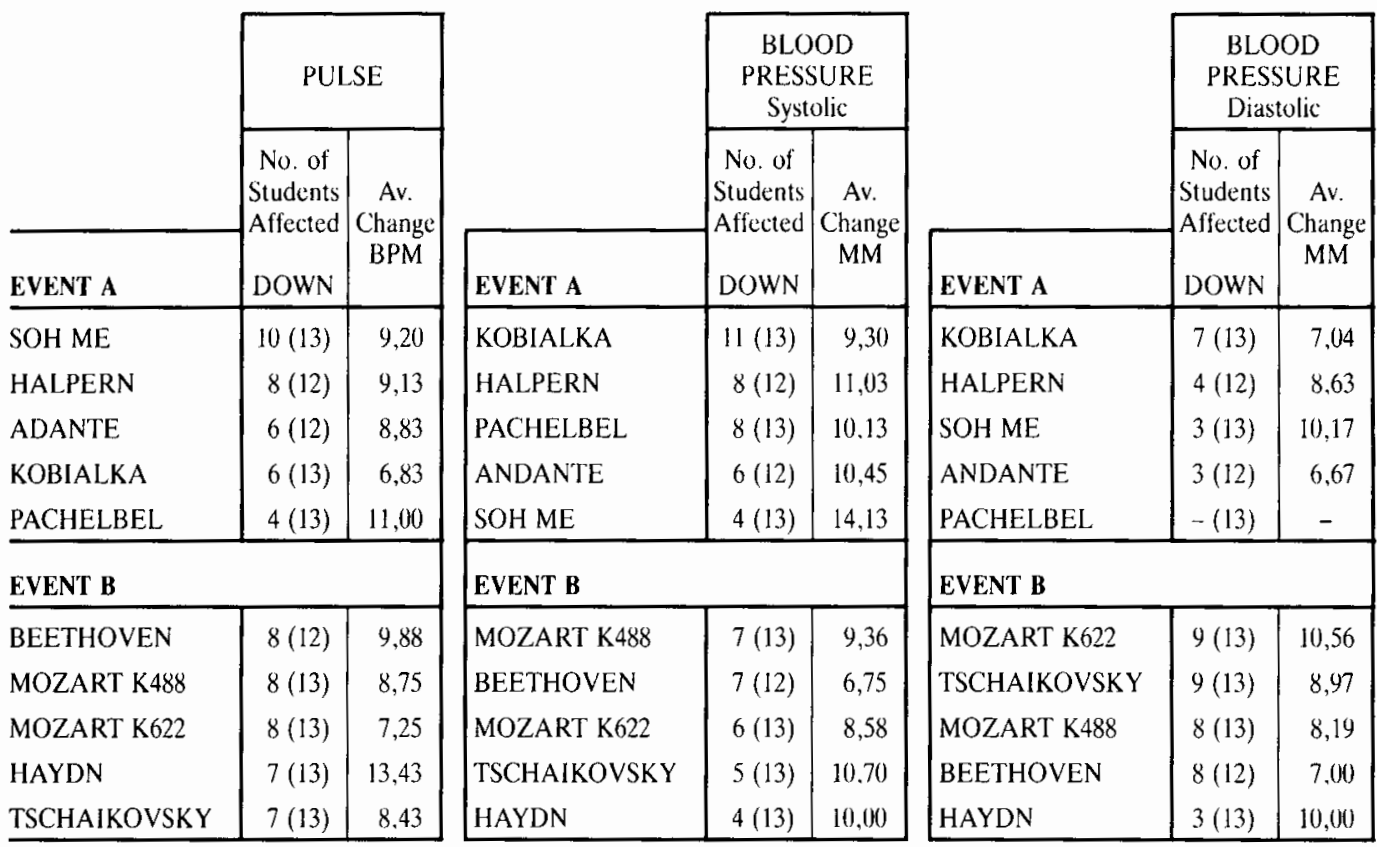

* The figures in brackets indicate the total number of students.

\section{Discussion: Hypothesis 1}

Certain kinds of music will induce more relaxation as measured by Blood Pressure and Pulse Rate than other kinds.

\section{EVENT A}

Pulse Rate Two pieces, Soh Me and Halpern, seem to indicate the induction of more relaxation than the other pieces and are therefore worthy of note.

Soh Me 10 (of 13) students' Pulse Rate went down by an average rate of 9,2 beats per minute

Halpern 8 (of 12) students' Pulse Rate went down by an average rate of 9,13 beats per minute

\section{Blood Pressure: Systolic}

Three pieces seemed to induce the most relaxation as measured by Systolic Blood Pressure: Kobialka, Halpern and Pachelbel.

Kobialka 11 (of 13) students' Systolic Pressure went down by an average rate of 9,30 millimetres of mercury

Halpern 8 (of 13) students' Systolic Pressure went down by an average rate of 11,03 millimetres of mercury

Pachelbel 8 (of 13) students' Systolic Pressure went down by an average rate of 10,13 millimetres of mercury.

\section{Blood Pressure: Diastolic}

No change appears to have taken place, except that the Kobialka affected the greatest number of students ( 7 of 13 ) 


\section{EVENT B}

Pulse Rate All the pieces appear to have caused the students Pulse Rate to decrease [7 or 8 (of 12 or 13)] but no one piece seemed to be significantly more effective than any other piece.

\section{Blood Pressure: Systolic}

There is no discernible tendency to indicate that any one piece had a significantly greater effect than any other except to note that the Haydn affected the least number of students.

\section{Blood Pressure: Diastolic}

It is interesting to note that the Haydn which affected the least number of students ${ }^{*}$ Systolic Pressure, affected significantly fewer students' Diastolic Pressure.

It is also noteworthy that the Haydn, as discussed above, caused the greatest average decrease in Pulse Rate with an average decrease of 13,43 beats per minute in 7 of 13 students.

\section{Conclusion: Hypothesis 1}

\section{EVENT A}

The expectation that the two baroque pieces (Pachelbel and Andante) would effect the greatest change in students' Pulse Rate and Blood Pressure, was not met.

The hope, not expectation, that Soh Me would indicate some change was met.

Soh Me in fact, affected the largest number of students' Pulse Rate. This, however, was not supported by Systolic Pressure where it was placed number five (of 5 pieces) nor by Diastolic Pressure where it was placed number three (of 5 pieces).

Halpern affected the second largest number of students' Pulse Rate; that is, it was placed second (of 5 pieces) in terms of effectiveness in lowering Pulse Rate. This is supported by Blood Pressure, both Systolic and Diastolic, in that it was also placed second.

Palchelbel was placed third in Systolic Pressure measurement, affecting 8 (of 13) students, with an average change of 10,13 millimetres of mercury. This is not supported at all by Pulse Rate (placed 5 of 5), nor by Diastolic Pressure where it was also placed last ( 5 of 5 ).

\section{EVENT B}

It was expected that the Tschaikovsky would effect the least change and this expectation was not met. It was also expected that the Beethoven Violin Concerto would effect the greatest change and this expectation was not met either. Generally, it appears that there does not seem to be any significant difference in the choice of music in terms of Pulse Rate nor in Blood Pressure (Systolic and Diastolic) other than to note, as has been indicated, that the Haydn effected the least amount of change (Systolic and Diastolic Pressure).

\section{Discussion: Hypothesis 2}

The music inducing most relaxation as measured by Blood Pressure and Pulse Rate will have common characteristics.

\section{EVENT A}

As can be noted from Table 3, the following music induced the most number of students' relaxation during Event $\mathrm{A}$

Soh Me (Pulse)

Kobialka (Blood Pressure: Systolic and Diastolic) 
It is noted further that in all three areas of measurement (Pulse Rate, Blood Pressure, Systolic and Diastolic), Halpern was placed in the second position.

It is interesting to note that all the above pieces of music have remarkably similar characteristics

- The instrumentation of all these pieces is similar; they all have a quality of sound "suspension"

The Kobialke uses the Vibraphone, the Halpern uses the Electric Piano and Soh Me uses the Alto Metallophone

- all these pieces do not follow a definite rhythmic pulse or pattern, the least dense being Soh Me and the most dense being the Kobialke

- the pitch range also moves from less dense (Soh Me; use of only two notes) to more dense (Halpern) and most dense (Kobialke) and the range seems to be focused on pitches above Middle $\mathrm{C}$ (256 vibrations per second)

- all these pieces give the impression of being "unstructured" to a greater or lesser degree.

\section{EVENT B}

In terms of the conclusion reached that there does not appear to be any significant difference in the choice of music, one is unable to isolate any particular characteristic of the music. However, as has been noted, as the Haydn effected the least amount of change, both in Systolic and Diastolic Pressures, it is interesting to note that this was the only piece which used a brass instrument (trumpet) as its solo instrument.

\section{Conclusion: Hypothesis 2}

It appears that the music for Mental Relaxation (Event A) which induced the most relaxation has common characteristics. No characteristics for First Concert (Event B) emerge due to the insignificance of that effect on the students' Pulse Rate and Blood Pressure other than a "negative difference" in solo instrumentation (Haydn Trumpet Concerto).

\section{Conclusion}

On the basis of the above discussion, it is concluded that certain kinds of music are more effective in lowering Pulse Rate, while other kinds of music are more effective in lowering Blood Pressure in a suggestopaedic setting. It is also concluded that, within the measurement "structures" of both Blood Pressure and Pulse Rate, some music effects greater change and therefore more relaxation, than other kinds.

It would appear that a significant tendency has emerged which indicates specific characteristics of the type of music which could be used in the Mental Relaxation phase. This music, it seems, needs to be "unstructured" (in the way that Soh Me, Halpern and Kobialke are unstructured), needs to use instrumentation which has a sound "suspension" quality, which also has an indefinite rhythmic pulse and which uses pitch levels greater than 256 vibrations per second (Middle $\mathrm{C}$ upwards).

Based on these apparent tendencies, one could perhaps suggest that further investigation be conducted in the use of the above mentioned types of music and other music with similar characteristics (perhaps certain kinds of Indian music) and with a larger sample of subjects. This further investigation would perhaps serve the purpose of validating these tendencies and could possibly isolate further musical characteristics as well as musical compositions which could then be profitably utilized in a suggestopaedic setting.

Editor's Note: further details regarding blood pressure and pulse rate readings are available from the author. 


\section{Bibliography}

ALEXANDER, L. 1982. Some preliminary experiments with SALT techniques music and exercise, paired words and narrative, word types, and meaning checks. The Journal of the Society for Accelerative Learning and Teaching, Vol. 7, No. 1, 41-49.

ALLEN, JOSEPH J. 1976. On teacher training experience at the Research Institute of Suggestology. The Journal of the Society for Accelerative Learning and Teaching, Vol. 1, No. 4, 304-316.

BANCROFT, W. JANE. 1976. The Lozanov language class. The Journal of the Society for Accelerative Learning and Teaching, Vol. 1, No. 1, 48-74

BANCROFT, W. JANE. 1985. Music therapy and education. The Journal of the Society for Accelerative Learning and Teaching, Vol. 10, No. 1, 3-20.

BLAIR, ROBERT W. 1982. Innovative approaches to language teaching. London: David and Charles.

BLANCHARD, B. EVERARD. 1979. The effect of music on pulse-rate, blood pressure and final exam scores of university students. Journal of Sports Medicine, 19, 305-308.

BORDON, R. \& Donald H. Schuster. 1976. The effects of a suggestive learning climate, synchronized breathing and music on the learning and retention of Spanish words. The Journal of the Society for Accelerative Learning and Teaching, Vol. 1., No. 1, 27-40.

BOTHA, H. LUDOLPH. 1986. Suggestopaedia for second language acquisition. Unpublished Doctoral Dissertation, University of Stellenbosch, South Africa.

BRISLAN, PATRICK S. 1984. A research project on the role of music in a suggestopaedic German course at the University of Adelaide. Proceedings of the First ALSA Conference, 25-44.

BUZAN, TONY \& Terence Dixon. (Without date). The evolving brain. London: David and Charles.

DHORITY, LYNN. 1984. Acquisition through creative teaching. ACT. The artful use of suggestion in foreign language instruction. The ACT Approach. Sharon, M.A.: Center for Continuing Development

GAMBLE, JAMES and DARLENE et al. 1982. The effects of relaxation training and music on creativity. The Journal of the Society for Accelerative Learning and Teaching, Vol. 7, No. 2, 111123.

LOZANOV, GEORGI. 1977. The Bulgarian experience. The Journal of the Society for Accelerative Learning and Teaching, Vol. 2, No. 3 \& 4, 85-95.

LOZANOV, GEORGI. 1978. Suggestology and the outlines of Suggestopedy. New York: Gordon \& Breach.

OSTRANDER, S. and N. \& L. Schroeder. 1979. Superlearning. New York: Dell.

POLLOCK, CECILIA. 1979. Educational experiment: therapeutic pedagogy. The Journal of the Society for Accelerative Learning and Teaching, Vol. 1, No. 2, 95-99.

PHILIPOV, ELIZABETH RISOVA. 1975. Suggestopaedia: The use of music and suggestion in learning and hypermnesia. The Journal of the Society for Accelerative Learning and Teaching, Vol. 3, No. 2, 65-107.

RACLE, G. 1976. The key principles of Suggestopaedia. The Journal of the Society for Accelerative Learning and Teaching, Vol. 1, No. 3, 149-160.

RACLE, G. 1979. Music, pedagogy, therapy: Suggestopaedia. The Journal of the Society for Accelerative Learning and Teaching, Vol 4, No. 3, 133-152.

REDMOND, ANNE. 1984. Influence of music on human behaviour. The Journal of the Society for Accelerative Learning and Teaching, Vol. 9, No. 2, 151-156. 
RENDER, G.F., \& C.R. and C.E. Hull. 1984. The effects of guided relaxation and baroque music on college students' test performance. The Journal of the Society for Accelerative Learning and Teaching, Vol. 9, No. 1, 33-40.

SCHUSTER. D.H. 1985. The effects of background music on vocabulary learning. The Journal of the Society for Accelerative Learning and Teaching, Vol 10, No. 1, 21-42.

SCHUSTER, D.H. \& David Mouzon. 1982. Music and vocabulary learning. The Journal of the Society for Accelerative Learning and Teaching, Vol. 7, No. 1, 82.

SCHUSTER, D.H. \& Rebecca Pansegrau. 1977. The effect of background music volume relative to speaking volume, previous list exposure and sex of subject on learning rare English words. The Journal of the Society for Accelerative Learning and Teaching, Vol. 2 (1 \& 2), 20-26.

STEIN, BARBARA L., C.A. Hardy \& Herman Totten. 1982. The effect of baroque music and imagery on vocabulary retention. The Journal of the Society for Accelerative Learning and Teaching, Vol. 7, No. 4, 341-356. 